\title{
Development Challenges of Game-Changing Entry System Technologies From Concept to Mission Infusion
}

\author{
Ethiraj Venkatapathy \\ NASA Ames Research Center \\ Moffett Field, CA 94035 \\ ethiraj.venkatapathy-1@nasa.gov \\ Jay Feldman \\ AMA Inc. \\ Moffett Field, CA 94035 \\ jay.d.feldman@nasa.gov
}

\author{
Robin Beck \\ NASA Ames Research Center \\ Moffett Field, CA 94035 \\ robin.a.beck@nasa.gov \\ Peter Gage \\ Neerim Corp. \\ Moffett Field, CA 94035 \\ pgage@neerimcorp.com \\ Paul Wercinski \\ NASA Ames Research Center \\ Moffett Field, CA 94035 \\ paul.wercinski@nasa.gov
}

\author{
Donald Ellerby \\ NASA Ames Research Center \\ Moffett Field, CA, 94035 \\ donald.t.ellerby@nasa.gov \\ Michelle Munk \\ NASA Langley Research Center \\ Hampton, VA 23681 \\ Michelle.m.munk@nasa.gov
}

\begin{abstract}
NASA's Space Technology Mission Directorate (STMD) and the Game Changing Development Program (GCDP) were created to develop new technologies. This paper describes four entry system technologies that are funded by the GCDP and summarizes the lessons learned during the development. The investments are already beginning to show success, mission infusion pathways after five years of existence. It is hoped that our experience and observations, drawn from projects supported by the GCD program/STMD, Orion and SMD can help current and future technology development projects. Observations on fostering a culture of success and on constraints that limit greater success are also provided.
\end{abstract}

\section{TABLE OF CONTENTS}

1. INTRODUCTION AND BACKGROUND 2. NASA'S CURRENT TECHNOLOGY DEVELOPMENT STRATEGY 3. THE FOUR ENTRY SYSTEM TECHNOLOGIES: BACKGROUND AND CURRENT DEVELOPMENT STATUS 3

4. OBSERVATIONS AND LESSONS LEARNED............... 8

5. CONCLUDING REMARKS .................................... 10 ACKNOWLEDGEMENTS ............................................ 11 REFERENCES.........ERROR! BOOKMARK NOT DEFINED.

\section{INTRODUCTION AND BACKGROUND}

When President Kennedy declared "We choose to go to the Moon in this decade," NASA successfully met the President's "hard challenge", and thereby became the preeminent space technology organization in the world. President Kennedy noted, "that goal will serve to organize the best of our energies and skills", and the NASA organization was indeed propelled to unparalleled successes in human and robotic spaceflight for over half a century. Viking achieved the first ever-successful landing on Mars, and Pioneer-Venus successfully delivered four probes into the harsh Venusian atmosphere. In the following decadeNASA successfully sent the Galileo Probe into Jupiter's atmosphere, the most demanding entry mission ever to be attempted. The entry into Jupiter at $48 \mathrm{~km} / \mathrm{s}$ produced heating equivalent to a ballistic missile nose-tip flying through the radiative heating of a thermo-nuclear explosion. The entry heat-pulse duration was $15 \mathrm{sec}$ and in that time, $50 \%$ of the entry aeroshell TPS was consumed by the heat, yet the delicate scientific payload was delivered successfully.

While NASA's strategy of robotic exploration through flyby, orbit and land was extended to the gas giants in the outer solar system, continued interest in Mars led to a series of small entry probes that delivered robotic rovers to the planet surface, starting with Pathfinder "sojourner" in the 1990s, followed by Mars Exploration Rover (MER) at the beginning of this century and Mars Science Laboratory (MSL) early this decade. On the human exploration side, the Space Shuttle and the Space Station programs have enabled long duration human presence in space.

Along with these great successes, there have been failures in both robotic science and human exploration missions. Renewed concentration on safety and reliability led to a conservative approach to mission selection and execution, and costly implementation. After the Columbia accident, the Shuttle Orbiter was deemed inherently unsafe. Major programs to develop new launch and re-entry systems for human spaceflight were initiated, but they prioritized the use of currently available technologies that would minimize system development time in order to minimize the period that NASA must depend on Russian vehicles for transport to and from the Space Station.

At the beginning of this century, NASA and the national leaders recognized that NASA must employ new approaches to restore its identity as an innovative and exploring organization. It was recognized that an investment in aggressive new technologies must be made. Budget limitations will 
always affect the scope of the technology development portfolio, but a strategy that prioritizes introduction of game-changing capability to enable new missions was needed.

\section{NASA'S CURRENT TECHNOLOGY DEVELOPMENT STRATEGY}

NASA created a new Space Technology Mission Directorate in 2011 to develop new technologies and foster a culture of innovation. This paper presents a perspective from the working level on progress towards these goals and some growing pains experienced.

NASA's then Chief Technologist, Dr. Robert Braun, in May of 2010, summarized the organizational vision ${ }^{1}$ by saying "We intend to take considerable risks to innovate. The Space Technology Mission Directorate (STMD) will invest in bold, broadly applicable disruptive technologies that Industry cannot tackle today. STMD seeks to mature the technology required for NASA's future missions in science and exploration while proving the capability and lowering the cost." The goal for STMD is to "rapidly develop, demonstrate and infuse revolutionary, high-payoff technologies" [1]. It is difficult to quickly measure the success of such an enterprise, because investment has to have both near term successes and also impact NASA's missions in the longer term. Though this paper is not about the STMD overall strategy and challenges, it is important to appreciate the environment under which an investment portfolio's management occurs. We believe that individual technology development projects should be conscious of the organizational context in order to derive support and be successful. True success goes beyond achieving the technology goals set within the project plan. True success is achieved with the continued development all the way to mission infusion. Figure 1 speaks to the investment strategy of the STMD [2]. While early stage investment is to encourage concepts to emerge through numerous small investments in Universities and small business programs, the expectation is that some of these high-risk investments will mature into midTechnology Readiness Level (TRL 3 - 6) development efforts.

The mid-TRL technology maturation projects, each a larger investment but fewer in number, are the responsibility of the Game Changing Development Program (GCDP) and SBIR Phase II and III. Some of the technology may find direct mission infusion and a few may require flight demonstration (TRL 7) for mission infusion. Through this broad approach risk and rewards are assessed as the technology matures. Those that have high value will feed into missions.

One of the earliest challenges for STMD was to identify NASA's technology needs. STMD developed a technology road map, which was reviewed by a NRC committee and subsequently revised. The Entry, Descent and Landing technology road map lays out current and future mission needs and identifies technology gaps.
The entry technology projects that are the basis of this paper are all funded currently under Game Changing Development Program (GCDP), which is tasked with "looking at a twoyear investment in getting TRL 3-6" [3]. Two of the four technologies, Adaptive Deployable Entry and Placement Technology (ADEPT) and Heatshield for Extreme Entry Environment Technology (HEEET) derived exploratory or formulation funding support as well as funds from the Center Innovation Funds (CIF) that allowed concepts to be matured to a level that made them selectable by GCDP. 3-D MAT and HEEET also benefited from a competitive Broad Area Announcement opportunity. The Conformal TPS effort investment started prior to the creation of the STMD and GCDP, so it was continued without competing for new start funding.

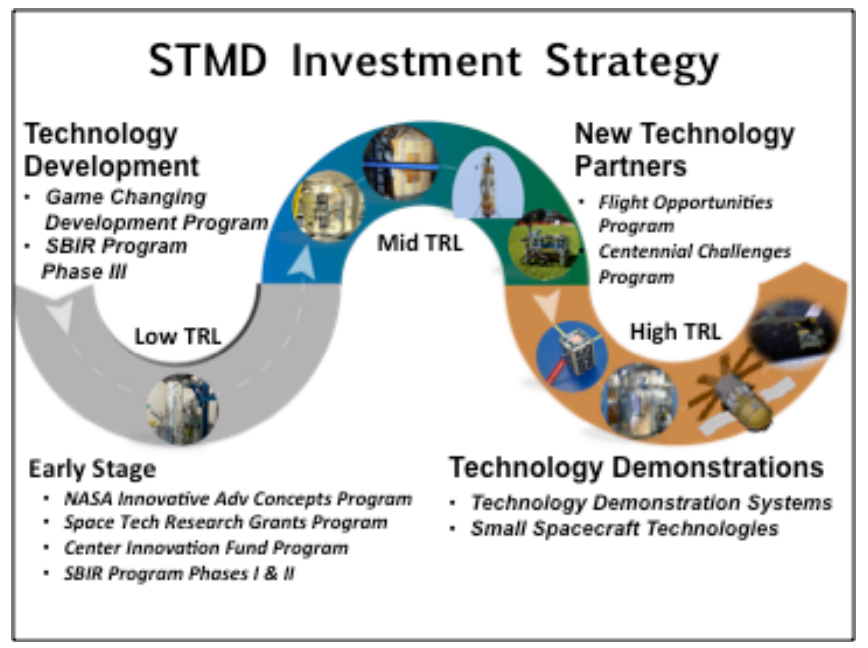

Figure 1. STMD investment strategy [2]

Investing in technologies that are "game changers" and maturing them from TRL 3-6 within 2 years is a stretch goal. In order to be successful, project selection and continuation have to be done with rigorous criteria. Current crite-

\begin{tabular}{|c|c|}
\hline \multicolumn{2}{|c|}{$\begin{array}{l}\text { Considerations for Game-Changing Development Funding } \\
\text { Game Changing Development Program View (May 2015) }\end{array}$} \\
\hline Appropriateness & Is this a broad technology and not engineering/research? \\
\hline Relevance/Alignment & $\begin{array}{l}\text { Is the technology aligned with Technology Roadmaps, } \\
\text { Decadal Surveys, etc.? }\end{array}$ \\
\hline Value Proposition & $\begin{array}{l}\text { What is the ratio of the potential benefits of the technology } \\
\text { to the cost to mature the technology? }\end{array}$ \\
\hline Leveraging/Partnering & Is the stakeholder/partner contributing resources? \\
\hline Customer Advocacy & $\begin{array}{l}\text { Do potential end users recognize the benefit and support the } \\
\text { activity? }\end{array}$ \\
\hline $\begin{array}{l}\text { Development Plan \& } \\
\text { Infusion Potential }\end{array}$ & $\begin{array}{l}\text { Is the activity well-planned, with appropriate schedule, } \\
\text { budget, advancement milestones, KPP's, and options? }\end{array}$ \\
\hline Acquisition Strategy & $\begin{array}{l}\text { Is the proposed acquisition strategy the most effective } \\
\text { strategy to mature the technology? }\end{array}$ \\
\hline Timeliness & $\begin{array}{l}\text { Is it critically important that this investment be initiated right } \\
\text { now? }\end{array}$ \\
\hline Maturity & $\begin{array}{l}\text { As a general guideline, GCD initiates investments at a } T R L=3 \\
\text { and matures the technology to } T R L=5 .\end{array}$ \\
\hline
\end{tabular}

Table 1. Selection factors for GCDP funding [3]

ria for new project selection are listed in Table 1. Looking back on the formulation phases of the four technology efforts that we will discuss in subsequent sections, some were 
strong in some selection factors and weaker in others. Some of these criteria are very challenging to meet, such as finding a stakeholder or partner to contribute resources to a TRL 3 technology. For entry system technologies, where NASA needs are unique, an investment by external partners may focus the technology narrowly to a specific mission. Truly "game changing" technologies require prolonged engagement with mission designers with the potential value of adopting a concept that is currently low-TRL. While these evaluation criteria play into selection in a collective way, technology developers indeed need to address each of the criteria for successful technology maturation and for mission infusion. The four technologies that will be discussed in the next section all address gaps identified in the road map.

\section{THE FOUR ENTRY SYSTEM TECHNOLOGIES: BACKGROUND AND CURRENT DEVELOPMENT STATUS}

The co-authors on this paper have been involved in leading the development of these four interrelated, but distinct, entry system technologies that are funded under GCDP. One of the co-authors, Ms. Munk, is the Principal Technologist responsible for the EDL technologies at the Space Technology Mission Directorate.

The four technologies are: 1) Conformal Ablative TPS materials, 2) 3D Multi-functional Ablative TPS (3D MAT) for the Orion compression pad, 3) Heat-shield for Extreme Entry Environment Technology (HEEET), and 4) Adaptive Deployable Entry and Placement Technology (ADEPT).

The four technologies can be grouped in various ways; here we identify two broad categories. The last three have a common basis in that they leverage advanced textile engineering via 3-D weaving, but the weaves differ from each other and are designed to accomplish a specific set of end goals. All of these technologies were proposed in order to expand the mission application space for both competed and designated missions. More details on these four technologies can be found in References [4] through [17].

\subsection{Conformal Ablative Thermal Protection System (CA- TPS):}

The motivation for proposing a new class of ablative material technology was based on the challenges experienced with the Mars Science Laboratory (MSL) and Orion MultiPurpose Crew Vehicle ablative TPS developments between the years (2003 - 2009). Phenolic Impregnated Carbon Ablator (PICA) was developed in the mid 1990's and proved to be a high performance and very mass efficient material with the successful flight of Stardust. PICA was one of several options considered for the Orion MPCV heatshield, and Orion matured both the PICA material manufacturing as well as design options for a tiled PICA system. When MSL experienced significant challenges with performance of its initial heat-shield material, Super Lightweight
Ablator (SLA), an alternate TPS had to be developed rapidly to avoid further delay. MSL then leveraged the Orion investments in PICA and a tiled PICA system enabled a timely mission launch. Orion, which is a human-rated system and would experience much higher heating conditions than MSL, down-selected the revived Avcoat material, the ablative TPS that was successfully used on Apollo heatshield. This decision was heavily influenced by the uncertainty associated with gap-filler performance in a tiled system.

PICA material starts with a rigid and brittle low-density carbon preform, which is infused with phenolic, then machined and bonded to the aeroshell structure. The small Stardust probe was able to use a single carbon preform so the heat-shield could be a single piece. Due to its larger size, the MSL heat-shield had to be assembled using tiles. The resulting gaps had to be filled, and for MSL the gapfiller material was Room Temperature Vulcanization (RTV) silicone rubber. Space-X's Dragon capsule uses a variant of PICA in a manner similar to the MSL tiled approach. During the early Orion studies, the fragile nature (low strength and low strain to failure) of PICA, which was planned to be installed on a metallic structure with a significantly different Coefficient of Thermal Expansion (CTE), drove a system design that had a large number of small tiles with Strain Isolation Pads (SIP) between the TPS and carrier structure. For MSL, the composite structure was much more compatible with the PICA properties, but the size of PICA tile was still limited by a number of considerations. PICA is made by infusing flat fiber form blocks, which have lower thermal conductivity through their thickness than in plane (since the carbon fibers tend to lie flat in the pre-form). In regions of high curvature on the heatshield, especially the shoulder, the maximum tile size is limited both by the shape that can be machined out of the preform and by the need to limit conductivity normal to the heatshield surface. Compared to SLA or Avcoat, PICA has a simpler material composition but integration into a heat-shield system is still complex.

The challenges experienced across multiple missions and multiple materials led to the realization that a flexible carbon felt, rather than a rigid carbon preform, could alleviate a number of system integration complexities while providing equivalent or better performance. Thus was born the Conformal Ablator concept, which replaces PICA's rigid preform with a felt that has lower conductivity and higher compliance. The felt is formed to a near-net tile shape before resin impregnation, which results in consistent thermal conductivity, regardless of curvature. The resulting conformal composites also have a much higher strain-to-failure than PICA allowing for larger tile sizes and easier integration.

Figure 2 shows the development history of Conformal TPS that began in 2009, prior to the creation of STMD/GCDP and the continued development to date. 


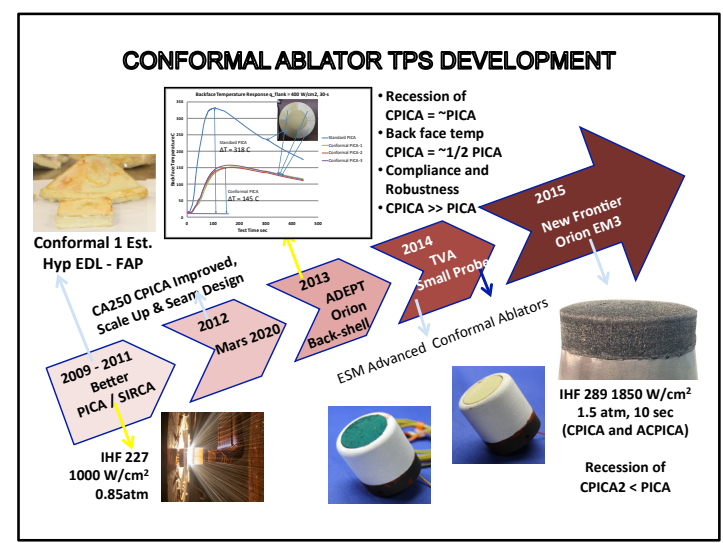

Figure 2. Conformal Ablator TPS Development History.

The initial target application was the Mars 2020 mission (with requirements similar to MSL) where the design heatflux anticipated is approximately $250 \mathrm{~W} / \mathrm{cm}^{2}$. Hence the key success criteria defined for the advanced ablative material development focused on replacing PICA for Mars missions. In 2012-13, structural and aerothermal (see Figure 3) performance of Conformal PICA was shown to be superior to that of standard PICA.



Figure 3. Comparison of backface temperature for Standard and Conformal PICA, for the same thickness and comparable densities. Arcjet testing shows the backface temperature of Conformal PICA is much lower for the same thickness, so it is more mass efficient for thermal protection.

While successful material development was indeed achieved at small scale, manufacturing scalability to achieve higher TRL required an industrial vendor with capability, expertise and resources. When Mars 2020 re-committed to PICA, the project's mission infusion potential, a key metric for continuation, had to be revisited. Orion MPCV back-shell was an obvious potential application, but Orion decided not to consider a low TRL alternative to the Shuttle-derived tile system it had been developing. Furthermore, in 2014 STMD/GCDP budgetary constraints required the program to trim its investments. The risk for project continuation was materializing and funding disruption during the critical development phase meant premature termination of the
Conformal TPS development despite the very good technical progress that had been made.

Fortunately, during this time a small innovative company, Terminal Velocity Aerospace (TVA), wanted to use Conformal TPS for their application, which is to bring back cube-sat size payloads safely to the ground from low earth orbit and also to collect reentry break-up data using small probes. The longer-term goal of TVA was to keep the cost of access to space low by manufacturing TPS in-house and hence they were looking for NASA technology. In return for the technology training, TVA was willing to obtain and share TPS flight performance data with NASA. NASA and TVA entered into an agreement with the support of GCDP/STMD, and the project continued with modified scope. The goal of manufacturability at larger scale was deferred to FY15 and will be completed in early FY16. The TVA partnership also meant Conformal TPS could get flight verification, at a small scale, for conditions relevant for the back-shell TPS for Venus and Saturn missions. Such flight verification could enable Conformal PICA to be adopted by New Frontiers or Discovery class missions, where achievement of TRL 6 is a threshold requirement for new technology insertion. Furthermore, STMD is evaluating whether Conformal could be an alternate heat-shield for Orion MPCV for Cis-Lunar return missions.

The key to the continued existence of Conformal TPS project, apart from the solid technical progress required for all projects, has been the flexibility to look for and accommodate emerging applications such as TVA, Orion, and planetary exploration applications.

\subsection{Technologies based on 3-D Woven TPS}

The next three technology projects leverage recent advances made in the textile industry, which has developed capabilities to weave 3-dimensional fabrics and preforms. Textile products have been used previously to make ablative TPS materials. For example, the carbon phenolic used in rocket nozzles, ballistic missiles and for entry probes such as Pioneer-Venus and Galileo, starts with 2-D carbon fabric. However, the use of customized 3-dimensionally woven preforms as substrates for TPS material development is novel. The preforms used herein are tailored for the specific NASA mission application and leverage the flexibility of the $3 \mathrm{D}$ weaving approach.

In order to evaluate the potential of 3-D weaving technology for thermal protection applications, a one-year exploratory effort was selected by STMD under their first competed Broad Area Announcement in 2010. Using 3-D weaving, with and without resin infusion, a variety of ablative TPS materials were produced over a wide range of densities. 3D woven material with compositions and densities similar to PICA at the low end and carbon-phenolic at the high end (Figure 4) were manufactured and tested in the arc jet. 


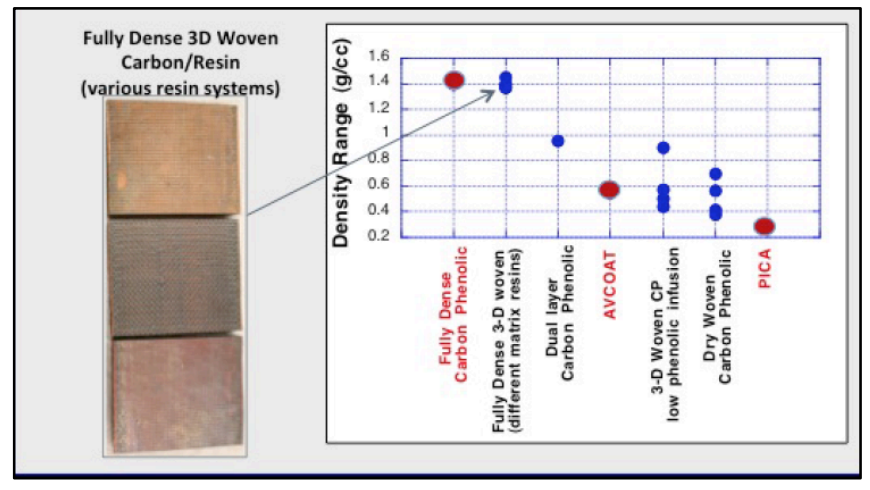

Figure 4. A family of ablative materials was manufactured and tested using 3-D weaving and resin infusion. The density of materials ranged from that comparable to PICA to that of fully-dense carbon phenolic.

A variety of fiber compositions, fiber volume fractions, weave architectures and resin systems were explored. Arc jet, mechanical and thermal property testing gave excellent insight into the performance of the family of materials. During this period, two independent development projects based on this exploratory effort were proposed and successfully initiated. One addressed the near-term Orion MPCV need for a lunar-return capable compression pad, and the other targeted the longer-term need for a more mass efficient ablative TPS for extreme entry environments.

The third technology effort that is based on 3-D weaving is the mechanically deployable entry system where an noninfused flexible and complex 3-D weave is folded for launch and ascent and then expanded like an umbrella to provide high drag for atmospheric entry.

\subsection{3-D Multi-functional Ablative TPS (3-D MAT)}

NASA's Orion crew module and service module are joined together during launch and space operations but separate prior to returning the crew to Earth. The two modules are initially held together by a retention and release mechanism that later facilitates separation prior to crew module reentry. A critical part of this component is the compression pad (Figure 5), which serves as part of the heat-shield and has both structural and aerothermal performance requirements.

Just prior to entry, the Orion crew module is separated from the service module by activating the explosive bolts. The compression pad experiences significant vibro-acoustic loads on launch/ascent, pyroshock loads upon explosive bolt detonation, thermal/structural loads on entry and is exposed to high aerothermal heating and molten metal upon atmospheric entry. These loads are too severe for a mid-density material such as Avcoat, the Orion acreage TPS.

The compression pad for the EFT-1 (earth orbit flight test) consisted of 2-D laminated carbon phenolic along with a steel insert as shown in Figure 5. This design was adequate for return from low Earth orbit, but not for higher energy
Lunar-return conditions, so a new design was needed for future missions.

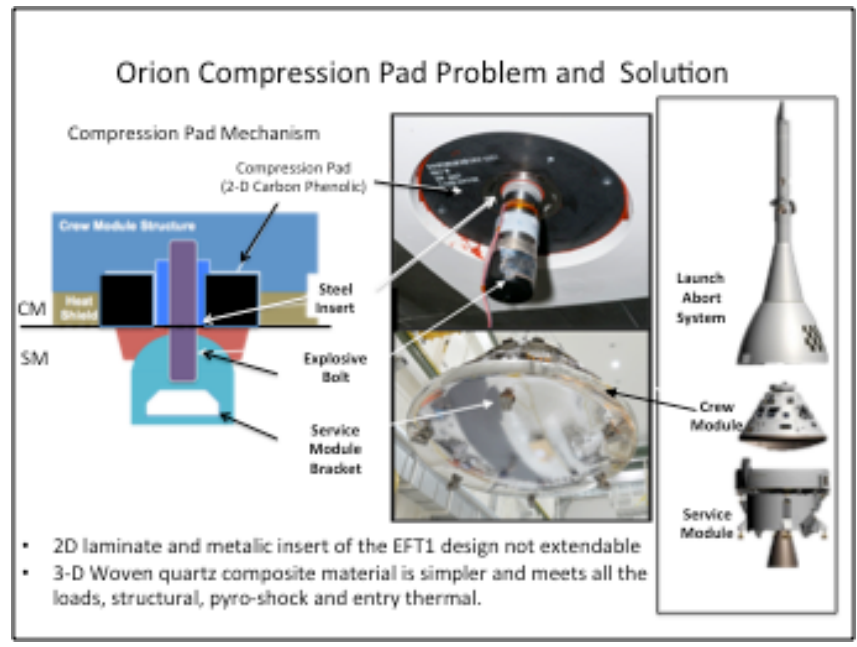

Figure 5. Schematic and photograph of the compression pad mechanism that keeps the Crew and Service modules connected during launch and space operations but allows the crew module to separate prior to entry. The EFT-1 flight test design was predicted to have negative margins for lunar return and beyond.

In 2011, the Orion project was searching for a material solution. As a result of the experience gained in the 3-D woven TPS effort described earlier, a proposal was accepted by GCDP and Orion to explore suitability of a fully-dense 3-D, woven TPS material. A two-phase approach was undertaken wherein phase 1 established feasibility for meeting the Orion requirements via material manufacture, property testing and analysis. Initial success allowed us to proceed to phase 2, which focused on manufacturing scale-up and developmental such as material property characterization, arc jet testing, thermal response model development and structural analysis. The effort was coordinated with Orion's EM-1 development to facilitate the compression pad redesign for the EM-1 mission (2018 launch). Success in phase 2 would enable Orion to adopt the material and pursue manufacturing for the flight.

Weaving of 3" thick by 12 " wide by 13 " long 3 -D orthogonal quartz-fiber preforms with very high fiber volume was the first of many technical challenges. The weaving vendor, Bally Ribbon Mills, undertook significant development including loom hardware re-design and modification. The second biggest challenge was complete resin infusion (undetectable voids) and curing of the large-scale preforms for achieving the quality and performance required for this human-rated mission. The large size of the preforms and high fiber volume fraction complicated the resin infusion, which required significant experimentation and development with a variety of approaches prior to success with San Diego Composites. The time criticality of Orion's launch schedule could only be met with the diligence of the entire team including government and vendor partners. 
The 3-D MAT project exceeded expectations and delivered a material that out-performed the original goal. The Orion project has baselined 3-D MAT as the compression pad material for all future Orion MPCV missions. In addition, Orion is beginning to use it in other locations on the vehicle, where the combination of structural and thermal loading is consistent with its capability.

In just 3 years, the 3-D MAT project conceived and developed the technology and infused it into the Orion mission with active engagement from NASA and Lockheed Martin stakeholders. 3-D MAT is enabling for Orion with no other material solution being viable for the EM-1 (and beyond) compression pad. The technology was infused into Orion at TRL 5 and is undergoing further development to TRL 6 prior to the 2018 scheduled launch of EM-1. At the time of writing this paper, 31 billets of 3D-MAT have been delivered to Lockheed Martin for development testing and for integration as flight hardware. Such a timeline is what the project hoped for and STMD/GCDP considers as a stretch goal of a successful technology development project. GCDP recently named 3-D MAT as the " 2015 Game Changer of the Year" project. Some of the key elements that led to this project success will be addressed in the discussion section.

\subsection{Heat-shield for Extreme Entry Environment Tech- nology (HEEET)}

The conventional architecture for protecting the payload during hyper-velocity entry is a rigid aeroshell, which consists of a thermal protection system bonded to an underlying structure. The TPS is selected and sized to keep the structure at or below its allowable use temperature so that it can handle the applied loads throughout the mission. The function of the TPS is simply to protect the structure and interior payload from the thermal load and the design typically does not require the TPS to take structural loads.

Entry into Venus, outer planets such as Saturn, or very highspeed sample return missions are challenging due to extreme heat-flux and pressures encountered during entry. Carbon Phenolics (which are compositionally similar to PICA or Conformal PICA because they use carbon fiber and phenolic resin, but have much higher density) were used in Pioneer-Venus and Galileo probe missions. Since NASA has not flown such challenging missions in the past four decades, lack of availability of a key raw material (Avtex rayon) coupled with atrophy in the processing and manufacturing of these materials has eliminated the ability to manufacture carbon phenolic with proven heritage performance. This situation has put future missions at risk.

The 2011 exploratory 3D Woven TPS effort demonstrated feasibility for weaving a multi-layer, multi-compositional preform tailored for extreme entry environments. Such a system would not simply replace carbon phenolic but would provide a more mass efficient solution. Figure 6 shows a schematic of the cross-section of a multi-layer material designed by the HEEET project.

In 2013, STMD and SMD jointly funded a year-long formulation effort that then matured into a four year project start-

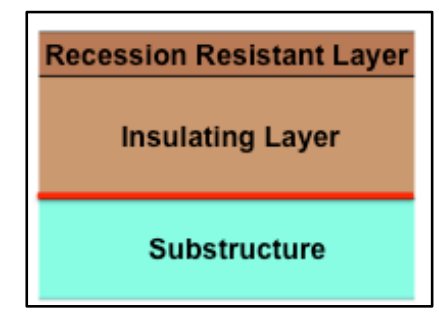

ing in 2014.

Figure 6. 3-D Woven Dual Layer system developed to withstand extreme entry environment with better mass efficiency and robustness compared to traditional 2-D laminate carbon phenolic.

The target was to allow mission proposals responding to Discovery-2014 Announcement of Opportunities (call for proposals) to consider using HEEET, which meant that HEEET would need to achieve TRL 6 by the PDR for selected missions. The four year development plan and progress to-date are highlighted in Figure 7.

Early manufacturing and testing showed that the acreage material was extremely robust, and behaved well at arc-jet conditions at which Carbon Phenolic fails. No unusual

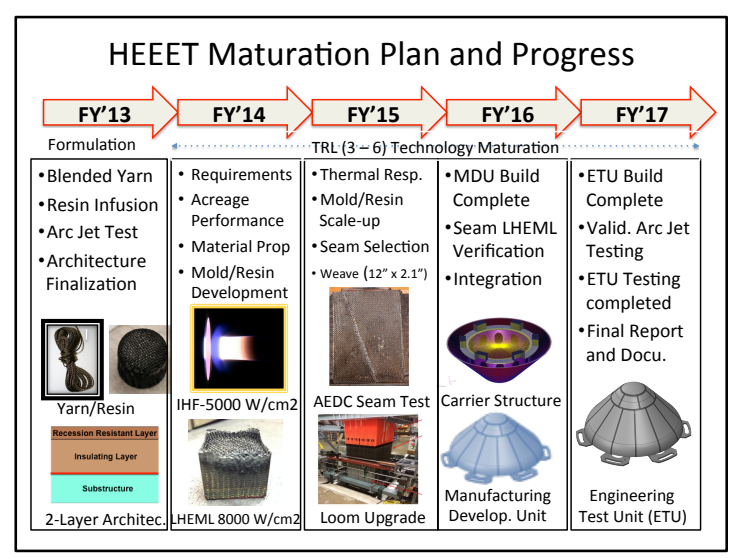

failure mode has been observed in any of the testing to date. Figure 7. HEEET technology maturation plan and key milestones.

Sizing studies show that HEEET will be lighter than carbon phenolic across a wide spectrum of missions to Venus, Saturn and higher speed sample return missions. The remaining challenges for the HEEET are in integration, especially for developing a robust seam design.

In 2014, SMD incentivized the use of HEEET by offering up to $\$ 10 \mathrm{M}$ beyond the mission cost cap, exempting the risks associated with HEEET development to TRL 6 from the TMCO review process and offered consultation from the HEEET team as Government Furnished Equipment (GFE) 
under the Discovery. The anticipated New Frontiers AO is another exciting opportunity for HEEET since entry missions targeting Saturn, Venus and Comet Sample Return are all expected to be proposed. SMD and STMD will jointly decide whether use of HEEET will be offered as a new technology (GFE) with similar incentive as under Discovery.

\subsection{Adaptable, Deployable Entry and Placement Tech- nology (ADEPT)}

The last technology in the discussion here is a class unto itself because it departs from the rigid aeroshell architecture. While we have grouped it within the Woven TPS category, because it leverages the advances in 3-D weaving, it is deployed in a distinct architecture that enables new mission operations.

Human missions to Mars will require landing large (20 MT to $40 \mathrm{MT}$ ) payloads, which is a grand challenge for Entry, Descent and Landing. The entry system required for hypersonic deceleration has to be much larger than launch systems can accommodate. A novel approach is to consider a deployable heat-shield (either inflatable or mechanical deployment) to reduce the ballistic coefficient at entry by increasing the drag area and still meet launch system constraints on payload geometry. ADEPT is a mechanically deployable entry system that resembles an umbrella with a fabric covering the ribs and struts as shown in Figure 8. The ADEPT concept was conceived in 2010 and preliminary design suggested its mass would be comparable to that of the hypersonic inflatable aerodynamic decelerator (HIAD) studied by NASA earlier for large mass Mars entry. Testing performed during that time also showed that a 3dimensionally woven carbon fabric is foldable and deployable and can provide thermal protection and high drag for deceleration as a rigid aeroshell would. This study then led to a technology maturation effort that primarily focused on a robotic mission to Venus. One of the challenges for Venus mission with a rigid aeroshell is the high peak deceleration, which was in the range of $200 \mathrm{~g}$ 's to $500 \mathrm{~g}$ 's for PioneerVenus and for Russian Venera probes. By lowering the ballistic coefficient via deployment of a large decelerator, early mission design studies showed that peak deceleration could be lowered to the range of $30^{\prime} \mathrm{g}-40^{\prime} \mathrm{g}$ for Venus lander missions. Such reductions enable use of sensitive scientific instruments, facilitate qualification of components through ground testing and reduce system structural mass. The first three years were focused on retiring highest risks by focusing on the carbon fabric, then on design, development and testing of a ground test article and integrated system design for a potential $6 \mathrm{~m}$ diameter deployable for a future Venus mission.

As progress was being made, the sister project HEEET was also proceeding successfully and the performance of HEEET was such that a Venus mission using HEEET could potentially achieve similar entry g'load by flying at low entry flight path angle without prohibitive TPS mass. Alt- hough the long-term goal of supporting human Mars missions is not impacted by the above finding, and there is still a viable mission infusion pathway (and need), the ADEPT team was challenged to refocus the technology development to achieve nearer-term mission infusion. Funding challenges experienced by STMD/GCDP also required ADEPT project to re-scope its activities at a much reduced budget. The ADEPT project re-vectored itself to advance the technology by going really small, with the rationale being that ground testing and sounding rocket flight test could fully qualify small systems at full scale and deliver high value for the technology development of future large systems.

In FY'14 and FY'15, the concept was tested in a low speed wind-tunnel [17] to ensure the mechanically deployed system is capable of handling flight-like dynamic loading and also retire any concern about aerodynamic flutter associated with the free edge of the fabric in the deployed configuration. In addition, an integrated system test of a $0.35 \mathrm{~m}$ scale configuration was conducted in the arc jet at heating conditions for a Mars entry. Also, conceptual designs have been completed for a sounding rocket flight test targeted for FY'16 to demonstrate deployment and aerodynamic stability of the system at supersonic through subsonic Mach numbers.

Currently the ADEPT configuration is one of three (the other two being HIAD and mid-L/D lifting configuration) being studied for future human Mars architecture.

Figure 8 shows the scale of ADEPT as originally conceived, and how it has evolved during its technology development adapting to constraints.

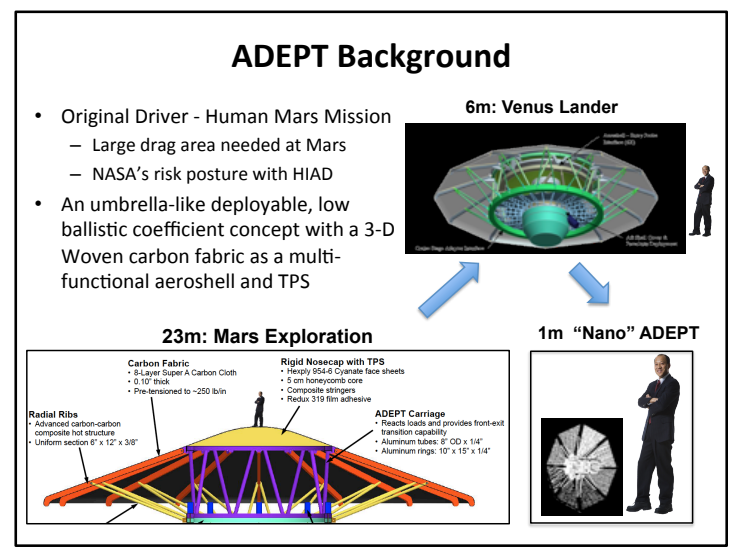

Figure 8. The changing scale of ADEPT, from concept studies to current focus, shown in this figure illustrates broad mission feasibility for a deployable, low ballistic coefficient decelerator. Much technology maturation can be accomplished efficiently (with respect to cost and schedule) at small scale

A point to be discussed later is that disparate technologies compete and sometimes advances in one technology may reduce the value proposition of the competing technology. A technology that can withstand such competition and yet continue to show value and be developed within budgetary 
constraints requires deep commitment and flexibility from all involved in the effort.

\section{OBSERVATIONS AND LESSONS LEARNED}

The primary purpose of this paper is to provide our experience in maturing and developing the entry system technologies while facing both technical and programmatic challenges. This discussion could help future technology development efforts to be better prepared. We also take a closer look at the original goals of STMD/GCDP and assess possible adjustments to organizational approaches that could improve future technology maturation activities.

\subsection{On Technology Maturation Time: Program Goal vs. Project Reality}

One of the challenges experienced by all the technology maturation efforts outlined previously is the stipulated GCDP goal for TRL maturation from 3 to $5 / 6$ within two years with a potential year extension. Technology maturation to TRL 6 includes both manufacturing and integration of the component technologies ready for mission infusion. This was perceived as a stretch goal but the initial approval and the funding all more or less used the same time line, despite a wide range of initial uncertainty and risk between the different efforts.

Including formulation, the overall timeline for the ADEPT, Conformal Ablative and HEEET exceeds 5 years. The outlier in our group of technologies is 3-D MAT, but even here infusion was achieved in 3 years while the original goal was 2 years. The 3-D MAT team understood all of the requirements fully, as the project team members were part of the initial Orion effort and had worked closely with the Orion team. Also, the Orion project was motivated and interested in 3-D MAT as no alternate solutions were deemed to be as viable. The 3-D MAT team adopted a phased approach to ensure viability of the material first and then address the more complicated challenges of scale-up and manufacturing.

ADEPT and HEEET are system developments and address more complex integration issues. ADEPT is particularly complex, and the goal of ADEPT for human Mars missions will require much more development time. It may be necessary to characterize the system capability as a set of technology developments, each of which may better align with the specified scope of GCDP activities. The difficulty here is that the combination of these technologies is needed to achieve game-changing mission infusion. A longer-term integrated project is also likely to be more cost-effective than a series of efforts with separate proposal and review burdens.

One conclusion we derive is that the original goal of $(2+1)$ years is not generally realistic, especially if the proposed technology is truly game changing. A more realistic stretch goal may be $(3+1)$ years and most likely those that are worthy of longer-term mission infusion would be $4+$ years.

\subsection{Risk - Project and Program Risks for Technology Maturation}

All new technologies have inherent and poorly characterized risks, which become visible at different stages of development. Successful technology development projects address them as they arise. Risks that are recognized late in the development consume more resources and time, and may degrade the perceived value of the proposed technology. Mission implementers do not want to depend on emerging technologies due to unknown risk picture. They often do not have full comprehension of the implementation and/or hidden risks. They prefer the use of known technologies with engineering fixes at a lower benefit as the unknown risks have higher cost and also take longer, hence a level of uncertainty that can derail a mission.

The mission selection process complicates the adoption of new technology. NASA's missions fall into two categories, namely, competed vs. designated missions. Robotic Science missions are competed except for a very small number of large Flagship missions. Vehicles for human exploration missions, such as Orion, are not competed but infusion opportunities are still rare. The competitive selection process is a bigger impediment for mission infusion, because it is difficult for mission proposers to show how a flight project would manage poorly understood or unknown risks in an emerging technology.

New technology development for entry systems is often perceived as inherently more risky than other technology areas because testing in fully relevant environments is often not feasible so the "test as you fly and fly as you test" approach is not viable. Heritage is highly valued because prior mission success indicates fully relevant performance. While it is true that technology development has inherent unknown risks, it is also true that previously used technologies carry different type of risks as well. NASA's missions are one of a kind, especially those that require entry and thermal protection systems. For example, TPS manufacturing is often unique and the only customer for it is typically NASA and as a result of infrequent need (low mission cadence), both expertise and manufacturing capability atrophy over time. This was the case for carbon phenolic and is applicable for a number of other TPS materials as well.

The challenge for a specific technology project is to assess the risk vs. benefit on a continual basis and to articulate the evolving situation to the program, to ensure continuation and prioritization for the right level of funding. Continuous engagement with stakeholders for viable mission infusion pathways strengthens end-user advocacy for annual allocation of program resources. Technologies that are truly game changing naturally carry higher risk posture and the benefit or value proposition are difficult to predict, especially earlier in the development and hence face an even more daunting challenge. 
Orion.

SMD and STMD are now working together to level the playing field for new technologies under the competed missions. HEEET was one of the first GCDP technologies to be identified as a new technology and incentivized by SMD for the Discovery missions. HEEET and ADEPT projects utilized Outer Planet Advisory Group (OPAG) and Venus Exploration and Analysis Group (VEXAG), two large advocacy groups for Outer Planets and Venus, to inform the Science Community about technology benefits. The technology projects also worked with mission proposers to generate endorsement from the stakeholders. Even with education and transparency, ADEPT was perceived as higher risk because there is no past experience in flying an umbrellalike deployable system at hypersonic speeds. One of the true characteristics of a Game Changing Technology is therefore perceptional and even a very high valued technology will face this challenge. STMD recognizes this problem, and provides pathways to flight demonstration so that system and flight risks are addressed prior to actual missions.

\subsection{On the Need to Define TRL and Exit Criteria with the support of the user community}

The ultimate goal of any new technology development project is to be adopted by a mission as soon as possible. Any time a new technology is not adopted at or near the end of the development project, parking or shelving of the technology will occur. Timely revival when future missions express the need can be challenging as capabilities and expertise atrophy over time. If the barrier to revival is too great, the technology investment may not pay off in the long run. It is critical that mission infusion is considered at the formulation phase and continuously reviewed throughout implementation. Specific criteria for technology readiness increments should be defined for each effort, along with exit success criteria. This cannot and should not be done by the technologist alone; it requires strong and enduring engagement with the user community.

Each of the four entry system efforts took a different approach and schedule to defining exit criteria and TRL. These experiences indicate that comprehensive definitions of exit criteria are needed at the formulation stage, and that the user community must be engaged at the very beginning to actively evaluate and advocate for the proposed technology. For truly game changing technologies it is particularly difficult to establish metrics, but also exceptionally important if advocacy is to endure over a long development phase. Another observation is that not all of the technologies have to be at TRL 6 for adoption by missions: the level of maturity needed for mission infusion can be negotiated with the customer. Documenting formal mission infusion agreement between the technology developer and the mission is ideal. Over the past few years GCDP has started implementing these agreements between STMD and missions and 3-D MAT was one of the earliest to do so with
For 3-D MAT, requirements and the development timeline were agreed upon at the very beginning. These were continually reviewed as requirements evolved and schedules changed. Technical challenges with 3-D MAT stretched the development time line until the margin for Orion's need date had shrunk close to zero. Working very closely with the end user and keeping them informed of progress was the key to the success of 3-D MAT.

For the HEEET project a focused workshop was organized and the community was asked to review the requirements, TRL definition and exit criteria. By engaging the broader user community interested in future mission proposals during the early phase of the project formulation, the HEEET project ensured comprehensive understanding in the mission community. Development of the project plan was made more efficient, because specific end-user concerns could be prioritized.

Conformal TPS was originally conceived as a replacement for PICA and hence the exit criteria were defined by achieving key performance parameters. While this was acceptable from the GCDP program and developing project plan, when the target missions, Mars 2020 and Orion, decided against considering Conformal, alternate customers had to identified and technology maturation had to be re-directed. The small probe application required the project to focus on the specific needs of TVA. Key challenges for integration and manufacturing readiness at larger scale still must be addressed prior to mission infusion for New Frontiers or Orion.

Each technology project went through a tailored process but the most important lesson learned is to define TRL and exit criteria with the help of the user community as early as possible.

\subsection{On Reference Missions, Requirements and Inde- pendent Reviews}

Carefully conceived requirements can form the backbone of a project plan, if the project tasks are aligned with the verification methods for each requirement. Requirement definition should be derived from mission need, so that development tasks are relevant to end users. Technology development should not be narrowly focused on a single mission but address a whole new generation of missions. This is especially challenging but also particularly important for "game changing" technologies. Requirement formulation is easier if the technology is more evolutionary.

Mission design studies should be done early, during formulation, as they shed light on the benefit of the technology. Using mission design studies during the life of the development, technology maturation projects can clearly articulate the benefit on a continual basis. Ongoing studies help to identify whens risks are retired and requirements are met. This framework promotes transparency and creates trust not 
only with the sponsoring program but also with the broader user community.

Periodic independent expert review adds significant burden on the technology development team but delivers significant value towards successful maturation as well as mission implementation. Reviews force rigorous focus on end goals and rigorous assessment of progress towards them.

3-D MAT again was a unique case because a single reference mission, namely Orion, was fully relevant and the requirements were well-defined. Also, the critical nature of the technology and the immediate need assured the Orion flight design team would be fully engaged on a regular basis.

The HEEET project, during formulation, did a variety of mission design studies, derived a set of requirements with the help of the user community and also established a standing review panel staffed by members from APL, GSFC, JPL, LaRC, KSC, JSC and Georgia Tech. The review panel findings and recommendations were evaluated and the project plan was modified as necessary. These independent review findings were used to inform the stakeholders including program officials of both the progress and the challenges.

Conformal project did not have an extensive approach to reviews because the initial goal was simply a material replacement for PICA. Later in the project, the lack of a specific target mission combined with the reduced resources complicated the opportunities for outreach to end users. Currently the interest in Conformal for New Frontiers and Orion will require re-baselining of requirements and an associated fundamental re-planning for TRL maturation from 5 to 6 .

Finally, the ADEPT project took a slightly different approach. ADEPT looked at a broad set of missions, including the human Mars mission, Venus lander missions and Mars robotic missions. The project derived both the list of risks to be retired and requirements to be met as part of the technology development consistent with these missions. In the second year, the focus was narrowed to New Frontiers class Venus lander missions. When the benefit of ADEPT to the Venus mission was found to be achievable with competing HEEET, development focus shifted to a sub-1m size without abandoning a development path to the larger scale human Mars mission. Such flexibility about intermediate milestones on a path to the ultimate goal is a key for a technology development that has a long maturation time. The ADEPT project did have independent reviews but not as frequently or as consistently as HEEET.

\subsection{On Competition vs. Collaboration - Ideas vs. People}

For technology development organizations such as STMD and GCDP to be successful, it is vitally important to simultaneously encourage competing ideas and yet ensure experts collaborate to support efforts even though some of the ef- forts may not succeed. This is a challenge within large organizations such as NASA where Centers compete for resources and there is a history of competition among experts and groups as well. While it is human nature to feel the pressure of competition, collaboration is vital for innovation. Collaboration levies burdens on teams that have members that are geographically and institutionally distributed, but if sufficient planning is paid to these details, multicenter collaborations can add strength to these efforts and achieve greater institutional commitment to the effort.

Every project within GCDP competes for limited program resources on an annual basis. Every technology project has to ensure that the evaluators understand and continue to support the project with adequate resources, whether or not the evaluation process is transparent. At the same time, each project must understand that the long-term success of NASA depends on the success of STMD and GCDP. Success at the program level may require some projects to receive reduced support. While STMD has espoused the philosophy that projects must aim high, take risks and failure is part of learning to do better, each project has to identify and manage risks with the clear intent to succeed. While failure of individual projects may be necessary for optimal performance at the program level, it is not optimal for participants in terminated or downgraded projects. Special attention is needed to assure technologists that the funding decisions do not necessarily correlate with the quality of their work. Sometimes the best work indicates the limited utility of a technology that appeared attractive before it was better understood.

The ADEPT project was proposed as an alternate to the inflatable or HIAD technology. The HEEET project was not initially perceived as a competitor to ADEPT, but mission analyses for Venus landed payload missions identified that it could perform well for this intermediate infusion opportunity. As HEEET matured, ADEPT had to reevaluate and re-vector its project plan. Conformal began with a limited goal and even though the performance data suggests conformal could be a very attractive option for NF missions and Orion, alternatives already in use are the competing technologies. The performance advantages of 3-D MAT were not fully embraced by the Orion program until it was clear that no heritage options were viable.

\section{CONCLUDING REMARKS}

Technology development organizations such as STMD (and GCDP) have to take risks and must invest in high-value / high-risk technologies with a consistent commitment over several years. Technology developers must foster a consistent and longer-term commitment from the program and potential end users, and they need to continually evaluate the reward to risk ratio of the progress. They need to monitor other competing technologies and they have a responsibility to inform the parent organization in a transparent way when they cease to be competitive. 
Our experience in the current NASA environment suggests the following:

- Truly game changing technologies need longer development time and consistent resource commitment. It is easier to focus on and achieve limited success with near term mission-focused technologies.

- Changes taking place within NASA and collaboration between mission directorates to promote the use of new and innovative technologies for mission infusion within the competed opportunities are very positive and encouraging. The four technologies described here have benefited and continue to benefit from this active engagement between technology developers and consumers.

- We are concerned that successful technology maturation under GCDP does not guarantee mission infusion. In order to ensure mission infusion, technology developers and organizations may need to "park" the technology until a mission need arises. Part of the challenge is capturing knowledge to facilitate effective revival when it is needed in the future. We believe STMD and GCDP need to address this challenge very soon.

\section{ACKNOWLEDGEMENTS}

The four projects involved numerous NASA centers, experts from around the country, review panel members and external vendors. We thank them for their support.

\section{REFERENCES}

[1] An interview by Dr. Robert Braun quoted from the following web reference. August 2010.

http://www.zdnet.com/article/nasa-chief-technologistrobert-braun-we-intend-to-take-considerable-risks-toinnovate/

[2] Ruether, J., "Overview of STMD Human Exploration Content," Humans to Mars Summit, $5^{\text {th }}$ May, 2015, Washington, D.C.

http://www.nasa.gov/sites/default/files/atoms/files/stmd humans to mars summit 55 15.pdf

[3] An interview by the GCDP Program Director, Steve Gaddis, September 1, 2012 from the reference on the web.

http://www.techbriefs.com/component/content/article/ntb /features/whos-who/14792."
[4] Beck, R., Arnold, J., White, S., Fan, W., Stackpoole, M., Agrawal, P., and Coughlin, S., "Overview of Initial Development of Flexible Ablators for Hypersonic Inflatable Aerodynamic Decelerators," 21st AIAA Aerodynamic Decelerator Systems Technology Conference and Seminar, 23 - 26 May 2011, Dublin, Ireland. AIAA 2011-2511.

[5] Gasch, M., Olson, M., Beck, R., Agrawal, P., Fan, W., and Thornton, J., "Conformal Phenolic Impregnated Ablator (C-PICA) TPS Development and Testing," JANNAF paper 3003, 60th Joint Propulsion Meeting, Colorado Springs, CO, April 29 - May 3, 2013.

[6] Milos, F., Gasch, M., and Prabhu, D., “Conformal Phenolic Impregnated Carbon Ablator (C-PICA) Arcjet Testing, Ablation and Thermal Response." AIAA SciTec/53rd AIAA Aerospace Sciences Meeting, 5-9 January, 2015, Kissimmee, Florida. (AIAA paper \# 2015-1448).

[7] Feldman, J. D.; Stackpoole, M. M.; Ellerby, D. T.; Venkatapathy, E. "Performance of High-Density Woven TPS Ablative Materials." 6th Spacecraft Propulsion Joint Subcommittee Meeting paper 2013-0002FK, May 2013. JSC CD-72.

[8] Stackpoole, M. M.; Feldman, J. D.; Ellerby, D. T.; Venkatapathy, E. "Performance of Mid-Density Woven TPS Ablative Materials.” 6th Spacecraft Propulsion Joint Subcommittee Meeting paper 2013-0002GE, May 2013. JSC CD-72.

[9] Stackpoole, M.; Feldman, J.; Venkatapathy, E. "Woven Thermal Protection System Final Report." NASA Ames Research Center. May 30, 2013.

[10] Venkatapathy, E., Ellerby, D., Gage, P., Stackpoole, M., Peterson, K., Chinnapongse, R., and Shelly, M., "NASA ARC Workshop: Defining Heatshield Capability Needs for Extreme Entry Environment, April 30, 2013, NASA Ames Research Center, Moffett Field, CA.

[11] Feldman, J., Venkatapathy, E., Wilkinson, C., and Mercer, K., "3-D Multifunctional Ablative Thermal Protection System," National Space \& Missile Materials Symposium; 22-25 Jun. 2015; Chantilly, VA.

[12] Ellerby, D., Venkatapathy, Stackpoole, M., Chinnapongse, R., Munk, M., Dillman, R., Feldman, J., Prabhu, D. and Beerman, A., "Woven Thermal Protection System Based Heat-shield for Extreme Entry Environments Technology (HEEET)," National Space and Missile Materials Symposium; 24-27 Jun. 2013; Bellevue, WA. 
[13] Venkatapathy, E., Beerman, A., Blosser, M., Chinnapongse, R., Ellerby, D., Fowler, M., Gage, P., Gasch, M., Peterson, K., Poteet, C., Prabhu, D., and Stackpoole, M., "Heat shield for Extreme Entry Environment Technology for near-term Robotic Science Missions and Longer-term Human Missions," An Invited Lecture Presented at the $11^{\text {th }}$ International Planetary Probe Workshop, June 20, 2014. Pasedena, CA.

[14] Venkatapathy, E., Arnold, J., Fernandez, I., Hamm, K., Kinney, D., Laub, B., Makino, A., and McGuire, K., Peterson, K., Prabhu, D., Empey, D., Dupzyk, I., Hyunh, L., Hajela, P., Gage, P., Howard, A., and Andrews, D., "Adaptive Deployable Entry and Placement Technology (ADEPT): A Feasibility Study for Human Missions to Mars," paper and presentation, 21st AIAA Aerodynamic Decelerator Systems Technology Conference and Seminar, 23 - 26 May 2011, Dublin, Ireland, AIAA Paper 2011-2608

[15] Fernandez, I.M., Venkatapathy, E., and Hamm, K., “ Transformable and Reconfigurable Entry, Descent and Landing Systems and Methods," June 2014. U.S. Patent 8,733,706.

[16] Venkatapathy E., Wercinski P., Beck R., Hamm K., Yount B., Makino A., Smith B., Gage P., Allen G., and Prabhu D., "Mechanically-Deployed Hypersonic Decelerator and Conformal Ablator Technologies for Mars Missions," an invited talk, Concepts and Approaches for Mars Exploration, held June 12-14, 2012 in Houston, TX.

[17] Smith, B., Venkatapathy, E., Wercinski, Yount, B., Prabhu, D., Gage, P., Glaze, L., and Baker, C., "Venus In Situ Explorer Mission Design using a Mechanically Deployed Aerodynamic Decelerator," Aerospace Sciences Conference, IEEE, Big Sky, Mt, March 2013

[18] Venkatapathy, E.," Modern Advances in Ablative TPS," A short course presented at the international Planetary Probe Workshop: the First Ten Years," an invited lecture, 10th International Planetary Probe Workshop, San Jose, California, June 17-21, 2013

[19] Smith, B., Yount, B., Kruger, C., Brivkalns, C., Makino, A., Cassell, A., Zarchi, K., McDaniel, R., Ross, J., Wercinski, P., Venkatapathy, E., Swanson, G., Gold, N., "Nano-ADEPT Aerolaods Wind Tunnel Test," IEEE Aerospace Conference, Big Sky, MT, March 2016.

\section{Biography}

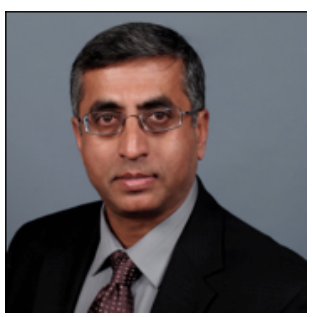

Ethiraj Venkatapathy is currently the Chief Technologist for the Entry Systems and Technology Division at NASA Ames Research Center. He received his B.Tech. in Aeronautical Engineering from the Indian Institute of Technology Madras, India, and his Ph.D. in Aerospace Engineering from the Iowa State University at Ames, Iowa. $\mathrm{He}$ is currently leading the technology development efforts, as the PM for Advanced TPS Materials project for the Game Changing Development Program and as the Principal Technologist for the mechanically deployable semi-rigid ADEPT project. In addition, he is the chief technologist for the Asteroid Threat Assessment Project.

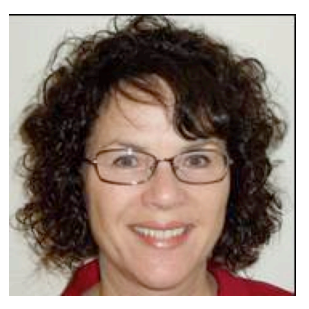

Robin A. S. Beck has been a member of the limited group of U.S. experts on developing, designing, testing, modeling ablative materials for use in earth and outer planetary entry, rocket nozzle exhausts, and laser environments for over 25 years. She received a BSME from Santa Clara University, and an MSME from Stanford University. After spending over 20 years at Aerotherm Corporation, Ms. Beck joined NASA Ames Research Center in 2006 and soon after was appointed to the Mars Science Laboratory (MSL) team as Cognizant Engineer for the MSL Thermal Protection System (TPS). After MSL successfully landed the Curiosity Rover on Mars, Ms. Beck became the technical lead of the CA-TPS element of the TPSM project under and has concentrated on the development of conformal ablative materials applicable for both heat shield and/or aft shell TPS with significant property improvements over their rigid counterpart.

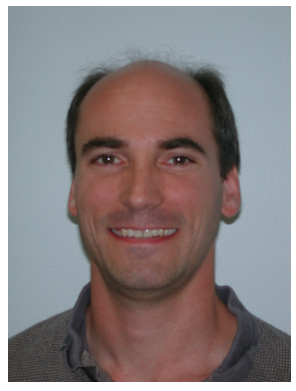

Donald Ellerby received a $\mathrm{PhD}$ in Materials Science and Engineering from the University of Washington in 1999. He has been with NASA Ames Research Center for $\sim 15$ years. $\mathrm{He}$ is currently the project manager for the Heatshield for Extreme Entry Environment Technology (HEEET) project, an SMD/STMD funded project developing a mass efficient 3D Woven Thermal Protection System targeting missions with extreme entry environments such as to Venus, Saturn and the Ice Giants. He has also served as a Branch Chief in the Entry Systems and Vehicle Development Branch within the Entry Systems Division at NASA Ames Research Center. And served as the Orion Multi-Purpose Crew Vehicle (MPCV) Thermal Protection System (TPS) Deputy System Manager 


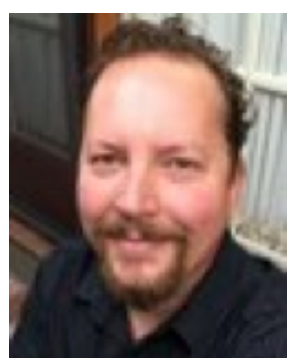

Jay Feldman is co-inventor of Woven Thermal Protection Systems which leverage $3 D$ weaving to produce a variety of heat shield materials tailored for different planetary entry mission requirements. Jay is also the lead for 3D$M A T$, a project that is developing a $3 D$ woven structural ablative material for use on the Orion heat shield compression pad and backshell. Jay received a B.S. in Chemistry from U.C. Irvine in 1996 and a Ph.D. in Chemistry from U.C. Berkeley in 2002. He has been a researcher in the area of thermal protection materials at NASA Ames Research Center for 13 years and recently joined AMA Inc. where he continues his $R \& D$ work at Ames.

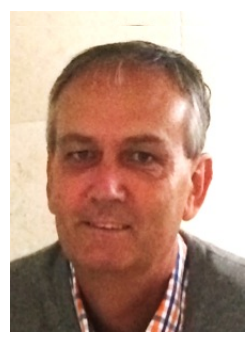

Peter Gage is president of Neerim Corporation, which provides aerospace design and systems engineering consulting services to government agencies and industry. He currently supports development of the thermal protection subsystem for Orion, leads systems engineering for HEEET, and performs project management for Martin UAV. He previously worked with Valador and ELORET, supporting NASA in systems architecture, space vehicle design and design software development. He has a B. Eng. degree from the University of Sydney and $M S c$ and PhD from Stanford. He is an associate fellow of AIAA. He was an associate editor for Journal of Spacecraft and Rockets, and is a past member of the Multidisciplinary Design Optimization TC.

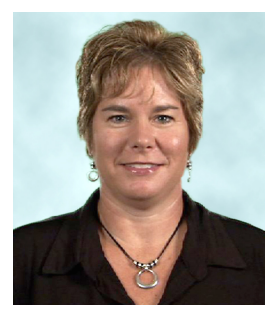

Michelle Munk earned a B.S. in Aerospace Engineering from Virginia Tech in 1991, and has been a NASA employee for over 27 years. She has served significant time at the Johnson Space Center in Texas, the Langley Research Center in Virginia, and the Marshall Space Flight Center in Alabama. Her technical background is in aerocapture, flight mechanics, and atmospheric entry trajectory simulation for both robotic and human exploration missions. She has managed several tasks in thermal protection systems, structures, and modeling. Since 2013, Ms. Munk has been on a detail assignment to NASA-Headquarters as the Principal Investigator for Entry, Descent and Landing (EDL) Technologies within NASA's Space Technology Mission Directorate (STMD). In this position, she advocates and coordinates NASA's EDL investments across the nine programs in STMD.

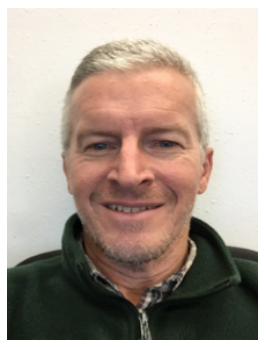

Paul Wercinski received a B.S. in Aerospace Engineering from the Pennsylvania State University in 1987 and a M.S in Aero/Astro Engineering from Stanford University in 1990. He has been with the NASA Ames Research Center for more than 30 years. He is currently the project manager for the Adaptable, Deployable Entry and Placement Technology (ADEPT) project since 2012. He has been involved in multiple areas within the Entry, Descent, and Landing (EDL) discipline at $N A S A$ over the past several decades. He had served a 1year assignment at NASA HQ in the Science Mission Directorate as program executive for the In-Space Propulsion Technology Program (2002-2003). He has served in line management roles at NASA Ames as well as participating in numerous planetary mission studies with an emphasis on EDL. 
